\title{
Hindbrain Herniation in Chiari II Malformation on Fetal and Postnatal MRI
}

\author{
(D) U.D. Nagaraj, (D) K.S. Bierbrauer, (1) B. Zhang, (D).L. Peiro, and (D)B.M. Kline-Fath
}

\begin{abstract}
BACKGROUND AND PURPOSE: As the practice of in utero repair of myelomeningoceles becomes more prevalent, knowledge of the expected MR imaging findings has become increasingly important. Our aim was to examine neuroimaging findings with a focus on hindbrain herniation and ventricular size in fetuses with open spinal dysraphism and to compare them with postnatal imaging features in groups undergoing prenatal-versus-postnatal repair.
\end{abstract}

MATERIALS AND METHODS: Single-center retrospective analysis was performed on MRIs of fetuses with open spinal dysraphism from January 2004 through July 2015 with available postnatal imaging. One hundred two fetuses were included. Reports from available fetal ultrasound were also examined. Images were reviewed by 2 board-certified fellowship-trained pediatric neuroradiologists. Descriptive analyses were performed to demonstrate the distribution of the imaging findings.

RESULTS: Thirty-two of 102 (31.3\%) fetuses underwent in utero repair of open spinal dysraphism; 68.6\% (70/102) underwent postnatal repair. Ninety-four of 102 (92.2\%) fetuses had cerebellar ectopia. Of those who underwent prenatal repair (26 grade 3, 6 grade 2), 81.3\% (26/32) had resolved cerebellar ectopia postnatally. Of those who had severe cerebellar ectopia (grade 3) that underwent postnatal repair, 65.5\% (36/55) remained grade 3, while the remaining $34.5 \%(19 / 55)$ improved to grade 2 . The degree of postnatal lateral ventriculomegaly in those that underwent prenatal repair $(20.3 \pm 5.6 \mathrm{~mm})$ was not significantly different from that in those that underwent postnatal repair $(21.5 \pm 10.2 \mathrm{~mm}, P=$ .53). Increased Chiari grade was significantly correlated with decreased head size for gestational age on fetal sonography $(P=.0054)$.

CONCLUSIONS: In fetuses with open spinal dysraphism and severe Chiari ll malformation that do not undergo prenatal repair, most have no change in the severity of cerebellar ectopia/Chiari grade. However, in fetuses that undergo in utero repair, most have resolved cerebellar ectopia postnatally.

ABBREVIATION: OSD = open spinal dysraphism

S ince the Management of Myelomeningocele (MOMS) trial revealed that prenatal surgery for myelomeningocele reduces the need for ventricular shunting and improves motor outcomes in infants with Chiari II malformation, the practice has become more widely available and is being offered and performed with increasing frequency. ${ }^{1}$ Fetal MR imaging continues to play an

Received September 19, 2016; accepted after revision December 19.

From the Department of Radiology and Medical Imaging (B.Z., B.M.K.-F.), Department of Pediatric Neurosurgery (K.S.B.), Division of Biostatistics and Epidemiology (B.Z.), and Department of Pediatric Surgery (J.L.P.), Cincinnati Children's Hospital Medical Center, Cincinnati, Ohio; and University of Cincinnati College of Medicine (U.D.N., K.S.B., B.Z., J.L.P., B.M.K.-F.), Cincinnati, Ohio.

Preliminary findings were presented as an oral presentation (O-307) at: Annual Meeting of the American Society of Neuroradiology and the Foundation of the ASNR Symposium, May 21-26, 2016; Washington, DC.

Please address correspondence to Usha D. Nagaraj, MD, Department of Radiology and Medical Imaging, Cincinnati Children's Hospital Medical Center, 3333 Burnet Ave, Cincinnati, OH 45229-3026; e-mail: usha.nagaraj@cchmc.org; @CincyKidsRad

http://dx.doi.org/10.3174/ajnr.A5116 essential role in evaluating fetuses prenatally not only to determine which candidates may potentially benefit from the procedure but also to evaluate associated anomalies to shed some light on prognostic information that will aid in counseling. ${ }^{2}$

Ample literature describes postnatal MR imaging findings of Chiari II malformation after postnatal repair of myelomeningoceles. ${ }^{3-5}$ However, the literature describing imaging findings in Chiari II malformation on fetal MR imaging is somewhat limited, mostly comprised of review articles with a few small studies. ${ }^{6-10}$ There are even fewer articles in the literature comparing neuroimaging findings between pre- and postnatal brain MRIs in patients with Chiari II malformation. ${ }^{2,11,12}$ In order to improve our understanding of the disease and improving outcomes, studies evaluating the neuroimaging findings in these patients both preand postnatally are becoming increasingly important, particularly studies that describe imaging parameters that can be easily implemented in clinical practice. 

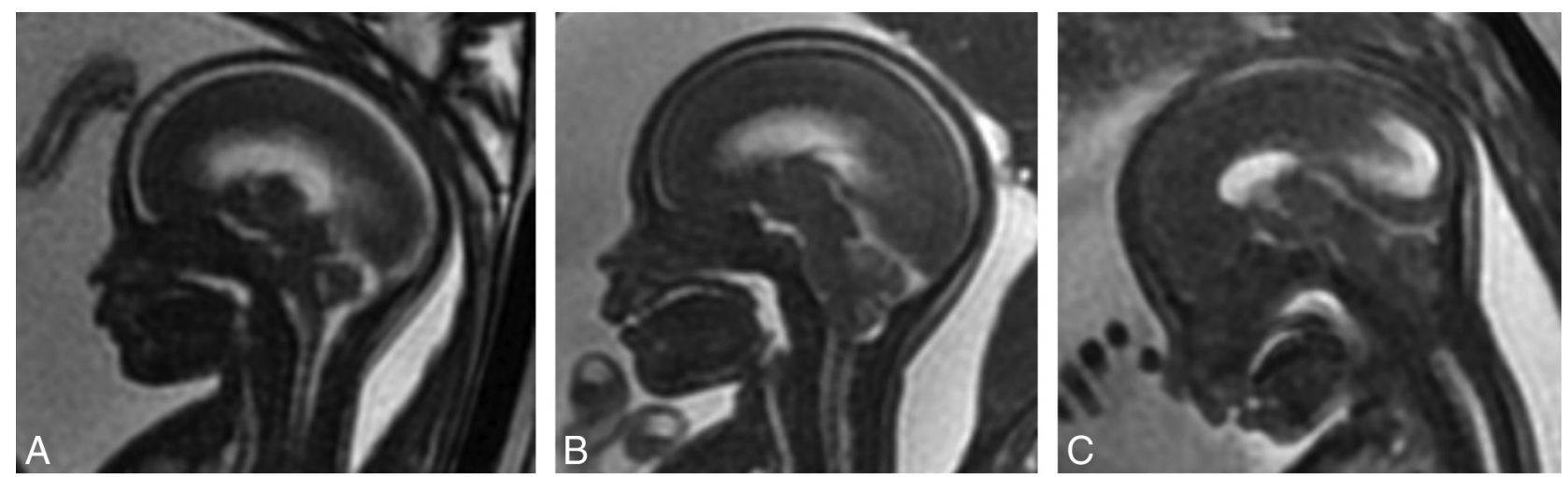

FIG 1. Grading of cerebellar ectopia on fetal MR imaging on sagittal FIESTA images of the brain. Grade $1(A)$ has no cerebellar ectopia with a patent cisterna magna and fourth ventricle. Grade $2(B)$ has cerebellar ectopia with an effaced fourth ventricle but a patent cisterna magna. Grade $3(C)$ has cerebellar ectopia with an effaced fourth ventricle and cisterna magna.

Our aim was to evaluate neuroimaging findings in fetuses with open spinal dysraphism (OSD) and to compare them with the postnatal imaging findings, with a focus on hindbrain herniation and ventricular size.

\section{MATERIALS AND METHODS Study Design}

This study was a single-center, retrospective review. The case list was compiled from all of the fetal MRIs performed between 2004 and 2015. Inclusion criteria encompassed fetuses with diagnosticquality fetal MRIs for OSD (either myelomeningocele or myelocele). ${ }^{13}$ Patients underwent either immediate postnatal repair or open in utero repair of OSD. Fetuses without cerebellar ectopia (grade 1) underwent postnatal repair only. Only fetuses with adequate available postnatal neuroimaging and clinical/neurosurgical follow-up were included. Criteria for adequate postnatal neuroimaging for this study included a diagnostic-quality MR imaging of the brain within the first 3 months of life. Determination of diagnostic-quality imaging was made at the neuroradiologists' discretion. A chart review was performed to obtain relevant clinical data, including reports from level II obstetric ultrasound when available. This study was compliant with the Health Insurance Portability and Accountability Act and approved by the institutional review board. The requirement for informed consent was waived.

\section{Scanning Parameters}

All fetuses included in our study were scanned prenatally on a 1.5T magnet at Cincinnati Children's Hospital Medical Center by using a Ingenia 1.5T (Philips Healthcare, Best, the Netherlands) or a 1.5T Signa HDxt (GE Healthcare, Milwaukee, Wisconsin) system. T2 single-shot FSE images of the brain were obtained in 3 planes: axial, sagittal, and coronal. Three-millimeter-section thickness no-gap interleaved images at $\leq 24$ weeks gestational age and 4-mm no-gap interleaved images at $>24$ weeks were used. Although this imaging protocol did not change during the study period, the TRs and TEs varied between each scanner and were changed at times of scanner upgrades to optimize image quality. At least 2 stacks in each plane were obtained to the radiologist's satisfaction. The smallest FOV possible was used. Axial DWI and T1 spoiled gradient-recalled images of the fetal brain were inconsistently implemented at the radiologist's discretion at the time of imaging. The postnatal imaging parameters varied because 1 of 6 available clinical magnets was used, and the routine use of volume $\mathrm{T} 13 \mathrm{D}$ spoiled gradient-recalled imaging was not implemented until 2009.

\section{Image Interpretation}

All images were reviewed by 2 board-certified radiologists (U.D.N., B.M.K.-F.), both with added qualifications in pediatric radiology and fellowship training in pediatric neuroradiology, one (B.M.K.-F.) with $>10$ years of postfellowship attending experience in pediatric neuroradiology in a large academic center, the other (U.D.N.) with 2 years of experience. The images were viewed on a PACS workstation. Only diagnostic-quality MRIs for the assessment of the fetal brain were included in our study; image quality was a subjective assessment made by the neuroradiologists. All patients included in our analysis also had diagnosticquality postnatal brain MRIs available for interpretation, as determined by the neuroradiologists ( 6 patients were excluded for this reason). The readers were blinded to the pre- and postnatal reported imaging findings at the time of interpretation and were also blinded to therapy (prenatal-versus-postnatal repair). Differences were resolved by consensus.

The degree of Chiari II malformation was determined by a grading scale in the fetus so that grade 1 was either normal or had a downward sloping tentorium and a normal patent fourth ventricle and cisterna magna without cerebellar ectopia; grade 2 had cerebellar ectopia with effacement of the fourth ventricle but a patent cisterna magna; and grade 3 had cerebellar ectopia and effacement of both the cisterna magna and fourth ventricle (Fig 1). This grading system was slightly modified from a previously reported system by Sutton et al ${ }^{2}$ in that we did not differentiate normal (grade 0 ) from grade 1 because the described difference was difficult to objectify. The same grading system was applied postnatally except that cerebellar ectopia with patency of the fourth ventricle or cisterna magna was considered grade 2 . The grading system was modified postnatally because unlike fetal MR imaging in which we did not see cerebellar ectopia when the fourth ventricle was patent, we frequently observed varying degrees of fourth ventricle and cisterna magna patency with cerebellar ectopia, so to maintain 3 groups, we modified the grading scale. 
Lateral ventricular size was measured in transverse dimensions in the axial plane at the level of the frontal horns or in the coronal plane at the level of the glomus of the choroid plexus, analogous to previously established fetal sonography guidelines. Fetal ventricular size was considered normal at $<10 \mathrm{~mm}$, mild-moderate ventriculomegaly at $10-15 \mathrm{~mm}$, and severe ventriculomegaly at $>15 \mathrm{~mm} \cdot{ }^{14}$ Postnatal ventricular size was considered normal at $<10 \mathrm{~mm}$, mildmoderate at $10-15 \mathrm{~mm}$, severe at $16-25 \mathrm{~mm}$, and extreme at $>25$ $\mathrm{mm}$. Third ventricle size was measured in the transverse dimension in the coronal plane and was considered enlarged in the fetus if it was $>3 \mathrm{~mm} \cdot{ }^{15}$

Extra-axial CSF spaces over the cerebral hemispheres were described as either completely patent or effaced (including both partial and complete effacement). The presence or absence of ventricular rupture/dehiscence was determined, with rupture being defined as the presence of direct communication between the lateral ventricle and the extra-axial CSF space over the cerebral convexity.

\section{Statistical Analysis}

Descriptive analyses were performed to demonstrate the distribution of the imaging findings. Continuous variables were presented as mean $\pm \mathrm{SD}$, and categoric variables were presented as number (percentage). A 2-sample $t$ test or 1-way ANOVA was used to detect the differences of continuous variables between different groups. The correlation between categoric variables was assessed by the $\chi^{2}$ or Fisher exact test when appropriate. All analyses were performed by using SAS, Version 9.4 (SAS Institute, Cary, North Carolina). A $P$ value of $<.05$ was considered statistically significant.

\section{RESULTS}

\section{Description of the Cohort}

A total of 102 fetuses (45 male, 57 female) met the criteria and were included in this analysis. Average gestational age at fetal MR imaging was $23.9 \pm 3.7$ weeks in the cohort as a whole, $24.6 \pm 4.2$ weeks in the postnatal repair group, and $22.4 \pm 1.5$ weeks in the prenatal repair group $(P=.004)$. Thirty-two of $102(31.3 \%)$ fetuses underwent open in utero repair of OSD, while the remaining $68.6 \%(70 / 102)$ underwent postnatal repair. The average gestational age at delivery was significantly lower in the prenatal $(31.5 \pm 4$ weeks $)$ versus the postnatal $(37.5 \pm 1.6$ weeks $)$ repair group $(P<.0001)$. Eighty-five of $102(83.3 \%)$ had a level II obstetric sonogram performed within a week of the fetal MR imaging, with images and/or a detailed report available for review. The average age at postnatal brain MR imaging was $19.7 \pm 21.9$ days.

\section{Posterior Fossa}

Imaging findings in the cohort as a whole are summarized in Tables 1 and 2. Seventy of 102 (68.6\%) fetuses underwent postnatal repair. Of these, $78.6 \%$ (55/70) had grade 3 and $10 \%$ (7/70) had grade 2 Chiari II malformation on fetal MR imaging. Of the 55 that were grade 3, 65.5\% (36/55) remained grade 3 (Fig 2), while the remaining 34.5\% (19/55) improved to grade 2 postnatally. Of the $12.7 \%(7 / 55)$ that were fetal grade 2 , 2 progressed to grade 3, 3 remained at grade 2, and 2 had resolved ectopia (grade 1) postnatally. Fetuses without cerebel-
Table 1: Summary of imaging findings on fetal MR in the cohort as a whole

\begin{tabular}{lc}
\hline \multicolumn{1}{c}{ Imaging Findings } & $\%$ of Cohort \\
\hline Cerebellar ectopia & $92.2 \%(94 / 102)$ \\
Fetal Chiari grade & \\
1 & $7.8 \%(8 / 102)$ \\
2 & $12.7 \%(13 / 102)$ \\
3 & $79.4 \%(81 / 102)$ \\
Effacement of prepontine cistern & $92.2 \%(94 / 102)$ \\
Lateral ventricular size & \\
$\quad$ Normal & $20.6 \%(21 / 102)$ \\
$\quad$ Mild-moderate ventriculomegaly & $57.8 \%(59 / 102)$ \\
Severe ventriculomegaly & $21.6 \%(22 / 102)$ \\
Third ventriculomegaly & $9.8 \%(10 / 102)$ \\
Lateral ventricular rupture & $1 \%(1 / 102)$ \\
Extra-axial CSF effacement & $92.1 \%(94 / 102)$ \\
\hline
\end{tabular}

Table 2: Summary of imaging findings on postnatal MR imaging in the cohort as a whole

\begin{tabular}{lc}
\hline \multicolumn{1}{c}{ Imaging Finding } & $\%$ of Cohort \\
\hline Cerebellar ectopia & $63.7 \%(65 / 102)$ \\
Postnatal Chiari grade & \\
1 & $36.3 \%(37 / 102)$ \\
2 & $26.5 \%(27 / 102)$ \\
3 & $37.3 \%(38 / 102)$ \\
Effacement of prepontine cistern & $14.7 \%(15 / 102)$ \\
Lateral ventricular size & \\
$\quad$ Normal & $4.9 \%(5 / 102)$ \\
Mild-moderate ventriculomegaly & $21.6 \%(22 / 102)$ \\
Severe ventriculomegaly & $51 \%(52 / 102)$ \\
Extreme ventriculomegaly & $22.5 \%(23 / 102)$ \\
Lateral ventricular rupture & $2.9 \%(3 / 102)$ \\
Extra-axial CSF effacement & $22.5 \%(23 / 102)$ \\
\hline
\end{tabular}

lar ectopia (grade 1) underwent postnatal repair only. Of the $11.4 \%(8 / 70)$ that did not have fetal cerebellar ectopia (grade $1)$, most $87.5 \%$ (7/8) did not progress to a higher grade postnatally (Figs $1 A$ and 3 ).

Thirty-two of $102(31.4 \%)$ fetuses underwent open in utero repair of OSD, $81.3 \%(26 / 32)$ with grade 3 and $18.8 \%$ (6/32) with grade 2 Chiari II malformation. Of those with grade 3, 76.9\% (20/26) had resolved (grade 1) cerebellar ectopia (Fig 4), 11.5\% (3/26) had improved ectopia (grade 2), and 11.5\% (3/26) had persistent grade 3 Chiari II malformation postnatally. Of those with grade 2, 100\% (6/6) had resolved cerebellar ectopia postnatally after prenatal repair.

\section{Ventricle Size and Extra-Axial CSF Spaces}

Imaging findings, including the degree of ventriculomegaly, the presence of at least partial effacement of the extra-axial CSF spaces over the cerebral convexities, and lateral ventricular rupture/dehiscence in the cohort as a whole, are summarized in Tables 1 and 2.

The degree of postnatal lateral ventriculomegaly in those that underwent prenatal repair $(20.3 \pm 5.6 \mathrm{~mm})$ was not significantly different from that in those that underwent postnatal repair $(21.5 \pm 10.2 \mathrm{~mm}, P=.53)$. The difference between the mean postnatal third ventricle size for the prenatal repair group $(4.7 \pm$ $2.8 \mathrm{~mm})$ and the postnatal repair group $(4.2 \pm 1.5 \mathrm{~mm})$ was also not statistically significant $(P=.29)$. Postnatal lateral ventricular size in the 8 patients with grade 1 Chiari II malformation on fetal 


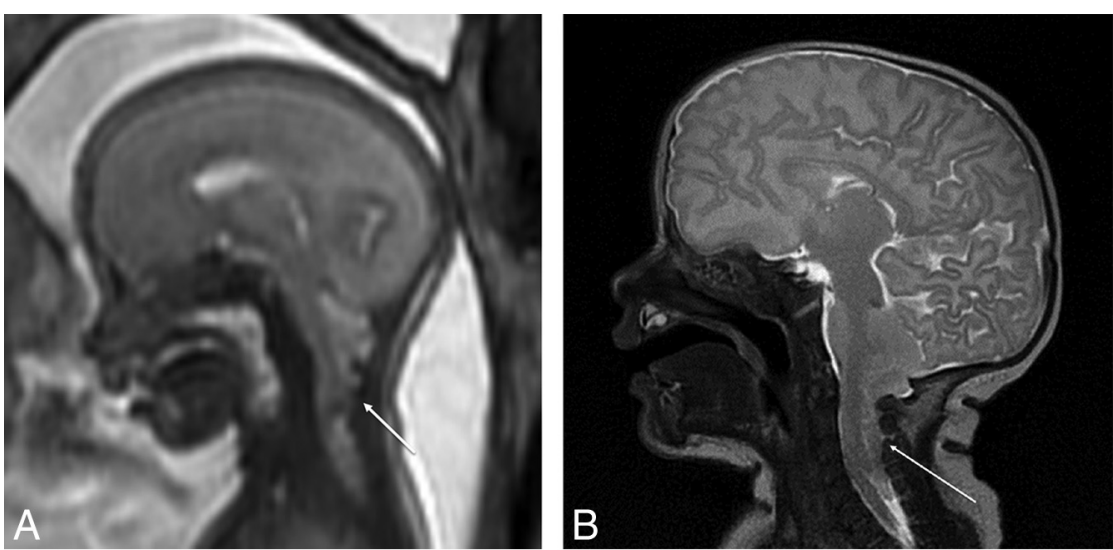

FIG 2. $A$ and $B$, Sagittal T2 SSFSE from fetal MR imaging performed at 24 weeks' and 5 days' gestational age $(A)$ demonstrates severe cerebellar ectopia or grade 3 Chiari II malformation (arrow). Note that there is also effacement of the prepontine cistern and extra-axial CSF spaces over the cerebral hemispheres. Sagittal T2 FSE from postnatal MR imaging of the same patient at 2 weeks of age after postnatal repair of OSD shows a persistent grade 3 Chiari II malformation (arrow).

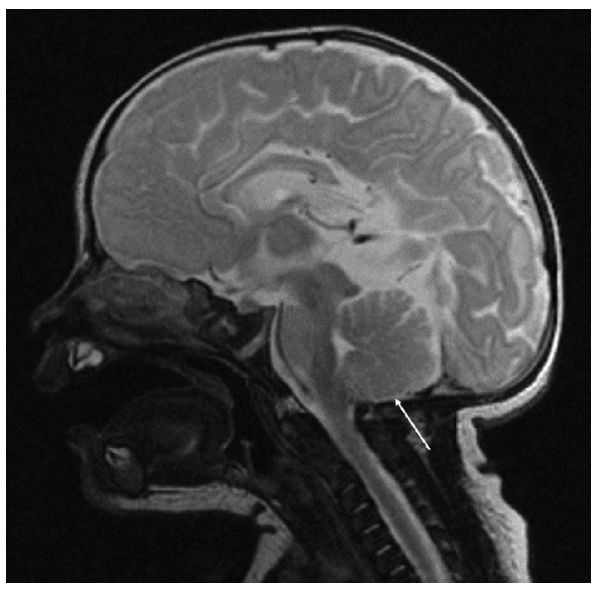

FIG 3. Sagittal T2 FSE from postnatal MR imaging in the same patient as in $\mathrm{Fig} 1 A$, status post postnatal repair of OSD at 11 days of age again demonstrates no cerebellar ectopia (arrow). Note the presence of other intracranial findings of a Chiari II malformation, including callosal hypogenesis/dysgenesis, a thickened massa intermedia, and tectal beaking.

MR imaging $(15.6 \pm 4.3 \mathrm{~mm})$ was significantly less than that in the remaining patients $(21.6 \pm 9.2 \mathrm{~mm}, P=.005)$. When we examined the change between the pre- and postnatal imaging findings, the prenatal lateral and third ventricle size was significantly smaller than the postnatal ventricular size in both the prenatal and postnatal repair groups $(P<.001)$. The Fisher exact test (for Chiari grade) and 1-way ANOVA (for ventricle size) showed a significant correlation between the prenatal Chiari grade and postnatal third ventricle size, with a $P$ value of .0443 . There was no significant correlation between prenatal Chiari grade and prenatal ventricular size (lateral and third ventricle) or postnatal lateral ventricular size. There was also no statistically significant relationship between lateral ventricular size and the presence of improved hindbrain herniation in either the pre- or postnatal repair groups.

Thirty-four of 102 (33.3\%) fetuses had a ventricular drainage catheter/shunt in place at the time of postnatal MR imaging, $47.1 \%$ $(33 / 70)$ of the postnatal repair group and 3.1\% (1/32) of the prenatal repair group. Of the 22 fetuses, 1 in the prenatal repair and

\section{Sonographic Findings}

\section{DISCUSSION}

21 in the postnatal repair group, with severe lateral ventriculomegaly $(>15$ $\mathrm{mm}), 54.5 \%(12 / 22)$ had a shunt at the time of postnatal MR imaging, compared with $27.5 \%(22 / 80)$ with a fetal lateral ventricular size of $\leq 15 \mathrm{~mm}$. All except $2(94.1 \%, 32 / 34)$ of the patients with a shunt on postnatal MR imaging had a grade 3 Chiari II malformation on fetal MR imaging. Only 12.5\% (1/8) of patients with grade 1 Chiari II malformation on fetal MR imaging had a shunt on postnatal MR imaging. The Fisher exact test showed a significant correlation between increased Chiari grade and the presence of prenatal extra-axial CSF space effacement, with a $P$ value of $<$ .0001. There was no significant correlation between Chiari grade and postnatal extra-axial CSF space effacement.

Reports from fetal ultrasound performed within 1 week of fetal MR imaging were available in 84 of the fetuses, 81 of which included amniotic fluid measurements. Of these, $96.3 \%$ (78/81) had reported normal amniotic fluid, 2.5\% (2/81) had decreased amniotic fluid (deepest vertical pocket, $\leq 2 \mathrm{~cm}$ ), and $1.2 \%(1 / 81)$ had increased amniotic fluid (deepest vertical pocket, $\geq 8 \mathrm{~cm}$ ). ${ }^{16,17} \mathrm{Head}$ circumference measurements were available in all 84 fetuses. Of these, $35.7 \%$ (30/84) had normal head circumference, $61.9 \%$ $(52 / 84)$ had decreased head circumference $(<10$ th percentile), and $2.4 \%(2 / 84)$ of fetuses had increased head circumference (>90th percentile) for gestational age. ${ }^{18}$ The Fisher exact test showed that an increased Chiari grade was significantly correlated with decreased head size, with a $P$ value of .0054 .

We describe pre- and postnatal MR imaging brain findings in patients with OSD with a focus on hindbrain herniation. We found that $92.2 \%$ (94/102) of fetuses had, prenatally and presurgically, cerebellar ectopia (grade 2 or 3), while $7.8 \%$ (8/102) did not. In those with severe/grade 3 cerebellar ectopia who underwent postnatal repair, $65.5 \%$ (36/55) remained grade 3, while the remaining 34.5\% (19/55) improved to grade 2. Of those who underwent prenatal repair, $81.3 \%$ (26/32) had resolved cerebellar ectopia postnatally (Table 3). We found a significant correlation between increased fetal Chiari grade and the presence of prenatal extra-axial CSF space effacement. We also found that the degree of postnatal lateral ventriculomegaly in those that underwent prenatal repair was not significantly different from that in those that underwent postnatal repair. Finally, we observed that an increased fetal Chiari grade was significantly correlated with decreased head size on fetal sonography.

The MOMS trial, in addition to describing the reduced need for shunting and improved motor outcomes in fetuses that undergo prenatal repair of a myelomeningocele, also reported improved hindbrain herniation. ${ }^{1}$ Smaller clinical studies in other centers have had similar results. ${ }^{19-21}$ Our findings are in keeping 
with these studies because we found that $81 \%$ of fetuses that underwent prenatal repair had resolved cerebellar ectopia postnatally, a result that was not observed in any of the fetuses that underwent postnatal repair. Our study adds to the clinical literature by describing in more detail the imaging findings on both pre- and postnatal MR imaging by adapting the grading system used by Sutton et $\mathrm{al}^{2}$ on fetal MR imaging, which can be applied to clinical practice. It seems clear that prenatal repair, by preventing leakage of CSF through the open neural tube defect, can progressively remodel the posterior fossa and revert the Chiari malformation to different degrees as we saw in the MR imaging studies of our patients. We also describe the evolution of the Chiari grade in the patients with postnatal repair in the cohort, including the $35 \%$ of fetuses with grade 3 Chiari who underwent postnatal repair and improved to grade 2; this improvement has not been previously described, to our knowledge.

The association between OSD and Chiari II malformation in infants has been long established and is accepted as a constant by many. ${ }^{4,3,13}$ The widely accepted unified theory of McLone and Dias $^{22}$ and McLone and Knepper ${ }^{23}$ describes how defective occlusion caused by an open neural tube defect precludes CSF accumulation and pressure within the developing cerebral ventricles, causing the findings of Chiari II malformation, including a small posterior fossa with hindbrain herniation. However, in our study, $8 \%$ of fetuses with postnatally confirmed OSD did not have cerebellar ectopia on fetal MR imaging. Although there is little in the literature describing this phenomenon, one other study described an incidence as high as $23 \% .{ }^{10}$ Our findings support the idea that not all fetuses with OSD have cerebellar ectopia. In addition, our study adds the finding that nearly all of these fetuses (7/8) did not develop cerebellar ectopia in the postnatal period after repair,
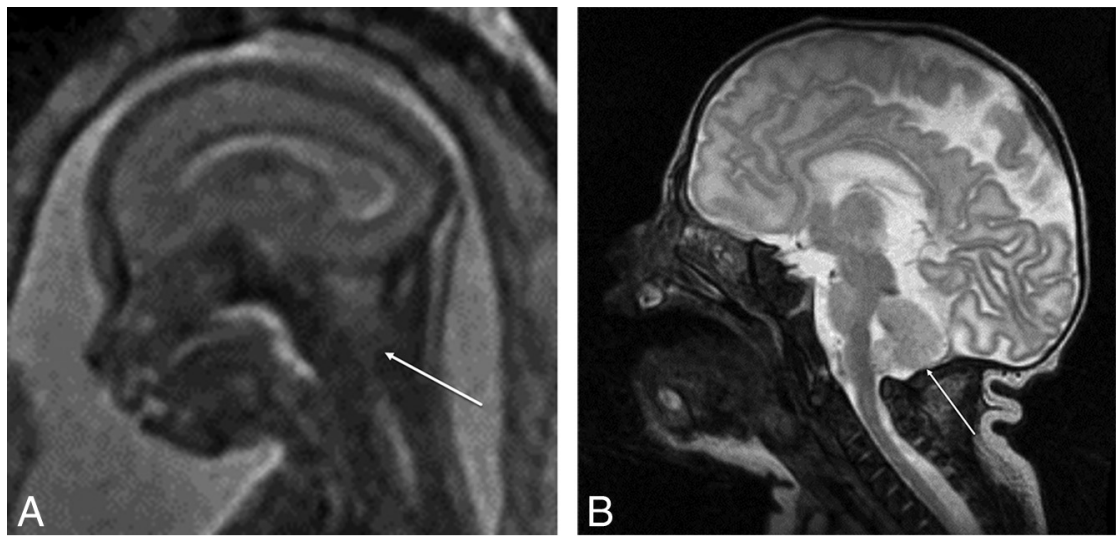

FIG 4. Sagittal T2 SSFSE from fetal MR imaging at 23 weeks' and 3 days' gestational age $(A)$ with severe or grade 3 Chiari II malformation (arrow). Sagittal T2 FSE image from postnatal MR imaging in the same patient at 2 weeks of age after in utero repair of OSD $(B)$ demonstrates resolved cerebellar ectopia (arrow). which suggests that hindbrain malformation in Chiari is unlikely to worsen. This suggestion may be helpful for prenatal counseling.

There is very little in the literature analyzing ventricle size in fetuses with OSD. One study found that on fetal MR imaging ventriculomegaly $(>10 \mathrm{~mm}$ ) was associated with the presence of cerebellar ectopia in fetuses with OSD. ${ }^{10}$ However, we demonstrate not only that there was no significant association between Chiari grade and ventricle size on fetal MR imaging but also that there was no statistically significant difference in postnatal ventricle size between the pre- and postnatal repair groups. This finding questions the role of ventricular size in shunt placement, because the MOMS trial and our own data illustrate a decreased need for shunting in patients who undergo prenatal repair. The decision to place a shunt does not rely on ventricle size alone, and other clinical factors are taken under consideration. ${ }^{1}$ In addition, our study only examines the initial postnatal brain MR imaging, so it is possible that differences in ventricular size may develop later and that the patients with prenatal repair may have stabilization of ventricular dilation that was previously obstructive. Evaluation of ventricle size may be clinically relevant because an update to the MOMS trial suggests that larger lateral ventricle size at initial screening is associated with an increased need for shunting and prenatal repair may not improve outcomes in fetuses with ventricles of $>15 \mathrm{~mm} .{ }^{24}$ In our study, only 1 fetus of 32 that underwent prenatal repair had severe ventriculomegaly $(>15 \mathrm{~mm})$. However, we observed that of the 22 fetuses with severe lateral ventriculomegaly in both groups combined, 54.5\% (12/22) had a shunt at the time of postnatal MR imaging, compared with $27.5 \%(22 / 80)$ with a fetal lateral ventricular size of $\leq 15$ $\mathrm{mm}$. This finding may suggest that in fetuses with a ventricle size of $>15 \mathrm{~mm}$, there may be a degree of obstruction that is more prone to progressively worsen.

Also very little in the literature exists describing the extra-axial CSF spaces over the cerebral convexities in fetuses with Chiari II, with only 1 study describing the depth of this space being lower in patients with Chiari II than in controls. ${ }^{10}$ Our study adds to the literature by not only describing a high association between CSF effacement and higher Chiari grade in fetuses but also showing that this association does not persist in the postnatal period after repair. When we examined head size, $62 \%$ of the fetuses in our study had decreased head circumference

Table 3: Benefits of prenatal-versus-postnatal repair by imaging

\begin{tabular}{lcc} 
& $\begin{array}{c}\text { Prenatal Repair Group } \\
(\boldsymbol{n}=32)\end{array}$ & $\begin{array}{c}\text { Postnatal Repair Group } \\
(\boldsymbol{n}=\mathbf{7 0})\end{array}$ \\
\hline \% of fetal grade 3 Chiari II malformation that remained grade 3 postnatally & $11.5 \%(3 / 26)$ & $65.5 \%(36 / 55)$ \\
\% of fetal grade 3 Chiari II malformation that improved or resolved postnatally & $88.5 \%(23 / 26)$ & $34.5 \%(19 / 55)$ \\
\% of fetal grade 2 Chiari II malformation that resolved postnatally (grade 1$)$ & $100 \%(6 / 6)$ & $28.6 \%(2 / 7)$ \\
\% that had a ventricular shunt catheter on postnatal MRI & $3.1 \%(1 / 32)$ & $47.1 \%(33 / 70)$ \\
\hline
\end{tabular}


on fetal sonography, which is consistent with previously published literature. ${ }^{18}$ We also found that an increased Chiari grade on fetal MR imaging is associated with decreased head size on fetal ultrasound, which has not been previously described. This finding may suggest that decreased head size is a reflection of effaced extra-axial CSF spaces and that fetuses with decreased head circumference may have more benefit from in utero repair than those with normal or increased head circumference. It may be interesting to perform further studies examining head size in utero after prenatal repair to see whether head size has the potential to normalize with this procedure.

Our study does have some limitations. First, the retrospective nature of this study limits its internal validity. Second, given that this is a single-institution study performed within a certain timeframe, the external validity may be limited as well. Along those same lines, our study likely has some degree of selection bias, given that these data are from one of the largest referral centers for fetal repair of OSD in the country, which we started performing at our institution in 2011. This may explain why the gestational age at fetal MR imaging is significantly less in the prenatal repair group compared with the postnatal repair group, as prenatal repair is typically performed before 26 weeks gestational age. However, differences in gestational age are unlikely to substantially affect our ventricular size data because it has been documented in the literature that lateral ventricular size remains relatively constant throughout gestation. ${ }^{25}$ Given that imaging studies were acquired during a 10 -year period on multiple different clinical magnets with periodic upgrades, the heterogeneity of scanning parameters may affect our results as well.

\section{CONCLUSIONS}

We describe imaging parameters on pre- and postnatal brain MR imaging in patients with OSD and find that in fetuses with severe Chiari II malformation that do not undergo prenatal repair, most $(65.5 \%)$ have no change in the severity of cerebellar ectopia/Chiari grade postnatally. In fetuses that undergo in utero repair, most $(81.3 \%)$ have resolved cerebellar ectopia postnatally. We also describe how cerebellar ectopia is not always present in fetuses with OSD on fetal MR imaging. We found no significant difference in the degree of postnatal lateral ventriculomegaly between those that underwent prenatal repair and those that underwent postnatal repair $(P=.53)$. Finally, we found a relationship between the degree of cerebellar ectopia with head size on fetal ultrasound and effacement of extra-axial CSF spaces on fetal MR imaging. The exact clinical implications of these findings are yet to be determined, and longterm clinical follow-up of these patients will be essential.

\section{REFERENCES}

1. Adzick NS, Thom EA, Spong CY, et al. A randomized trial of prenatal versus postnatal repair of myelomeningocele. N Engl J Med 2011; 364:993-1004 CrossRef Medline

2. Sutton LN, Adzick NS, Bilaniuk LT, et al. Improvement in hindbrain herniation demonstrated by serial fetal magnetic resonance imaging following fetal surgery for myelomeningocele. JAMA 1999;282: 1826-31 CrossRef Medline

3. Wolpert M, Anderson M, Scott RM, et al. Chiari II malformation: MR imaging evaluation. AJR Am J Roentgenol 1987;149:1033-42 CrossRef Medline

4. el Gammal T, Mark EK, Brooks BS. MR imaging malformation of Chiari II. AJR Am J Roentgenol 1988;150:163-70 CrossRef Medline
5. Geerdink N, van der Vliet T, Rotteveel JJ, et al. Interobserver reliability and diagnostic performance of Chiari II malformation measures in MR imaging, part 2. Childs Nerv Syst 2012;28:987-95 CrossRef Medline

6. Glenn OA, Barkovich J. Magnetic resonance imaging of the fetal brain and spine: an increasingly important tool in prenatal diagnosis, part 2. AJNR Am J Neuroradiol 2006;27:1807-14 Medline

7. Glenn OA. MR imaging of the fetal brain. Pediatr Radiol 2010;40: 68-81 CrossRef Medline

8. Righini A, Zirpoli S, Mrakic F, et al. Early prenatal MR imaging diagnosis of polymicrogyria. AJNR Am J Neuroradiol 2004;25: 343-46 Medline

9. Mignone Philpott C, Shannon P, Chitayat D, et al. Diffusion-weighted imaging of the cerebellum in the fetus with Chiari II malformation. AJNR Am J Neuroradiol 2013;34:1656-60 CrossRef Medline

10. Batty $\mathrm{R}$, Vitta $\mathrm{L}$, Whitby $\mathrm{EH}$, et al. Is there a causal relationship between open spinal dysraphism and Chiari II deformity? A study using in utero magnetic resonance imaging of the fetus. Neurosurgery 2012;70:890-98; discussion 898-99 CrossRef Medline

11. Papadias A, Miller C, Martin WL, et al. Comparison of prenatal and postnatal MRI findings in the evaluation of intrauterine CNS anomalies requiring postnatal neurosurgical treatment. Childs Nerv Syst 2008;24:185-92 CrossRef Medline

12. Adzick NS. Fetal surgery for spina bifida: past, present, future. $S e$ min Pediatr Surg 2013;22:10-17 CrossRef Medline

13. Tortori-Donati P, Rossi A, Cama A. Spinal dysraphism: a review of neuroradiological features with embryological correlations and proposal for a new classification. Neuroradiology 2000;42:471-91 CrossRef Medline

14. Melchiorre $\mathrm{K}$, Bhide $\mathrm{A}$, Gika $\mathrm{AD}$, et al. Counseling in isolated mild fetal ventriculomegaly. Ultrasound Obstet Gynecol 2009;34:212-24 CrossRef Medline

15. Sari A, Ahmetoglu A, Dinc H, et al. Fetal biometry: size and configuration of the third ventricle. Acta Radiol 2005;46:631-35 CrossRef Medline

16. Magann EF, Sandlin AT, Ounpraseuth ST. Amniotic fluid and the clinical relevance of the sonographically estimated amniotic fluid volume: oligohydramnios. J Ultrasound Med 2011;30:1573-85 CrossRef Medline

17. Sandlin AT, Chauhan SP, Magann EF. Clinical relevance of sonographically estimated amniotic fluid volume: polyhydramnios. $J$ Ultrasound Med 2013;32:851-63 CrossRef Medline

18. Coleman BG, Langer JE, Horii SC. The diagnostic features of spina bifida: the role of ultrasound. Fetal Diagn Ther 2015;37:179-96 CrossRef Medline

19. Moldenhauer JS, Soni S, Rintoul NE, et al. Fetal myelomeningocele repair: the post-MOMS experience at the Children's Hospital of Philadelphia. Fetal Diagn Ther 2015;37:235-40 CrossRef Medline

20. Faria TC, Cavalheiro S, Hisaba WJ, et al. Improvement of motor function and decreased need for postnatal shunting in children who had undergone intrauterine myelomeningocele repair. Arq Neuropsiquiatr 2013;71:604-08 CrossRef Medline

21. Hisaba WJ, Cavalheiro S, Almodim CG, et al. Intrauterine myelomeningocele repair postnatal results and follow-up at 3.5 years of age: initial experience from a single reference service in Brazil. Childs Nerv Syst 2012;28:461-67 CrossRef Medline

22. McLone DG, Dias MS. The Chiari II malformation: cause and impact. Childs Nerv Syst 2003;19:540-50 CrossRef Medline

23. McLone DG, Knepper PA. The cause of Chiari II malformation: a unified theory. Pediatr Neurosci 1989;15:1-12 CrossRef Medline

24. Tulipan N, Wellons JC 3rd, Thom EA, et al; MOMS Investigators. Prenatal surgery for myelomeningocele and the need for cerebrospinal fluid shunt placement. J Neurosurg Pediatr 2015;16:613-20 CrossRef Medline

25. Almog B, Gamzu R, Achiron R, et al. Fetal lateral ventricular width: what should be its upper limit? A prospective cohort study and reanalysis of the current and previous data. J Ultrasound Med 2003;22: 39-43 CrossRef Medline 